DOI: 10.23860/JMLE-2019-11-2-6

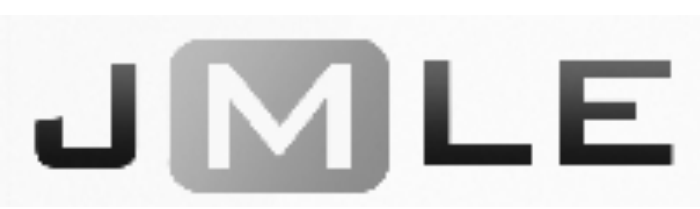

The National Association for Media Literacy Education's

Journal of Media Literacy Education, 11(2), 95 - 121

\title{
Measuring Media Literacy Inquiry in Higher Education: Innovation in Assessment
}

\author{
Evelien Schilder \\ RIPE NCC, The Netherlands \\ Theresa Redmond \\ Appalachian State University, USA
}

\begin{abstract}
The ability to critically access, analyze, evaluate, and create media messages is crucial in the process of becoming an informed and engaged citizen throughout life. Asking critical questions is not only a valuable dimension of media literacy, but also an indispensable aspect of participating in a democracy. Yet, measuring the effectiveness of media literacy is still a major challenge for the field. It is unclear to what extent people of all ages may engage in critical questioning habits with regards to media. To address this gap, we studied the changes in critical questioning habits for college-aged students enrolled in media literacy courses. To measure students' media literacy inquiry, we evaluated the questions they posed in response to viewing an advertisement. We analyzed questions by media literacy concept and by level of complexity before and after their participation in the media literacy courses. Findings revealed that after the media literacy courses, students' inquiries were more complex and involved more attention to key concepts related to production techniques and representations. Our study is significant as it reflects an innovative approach to media literacy assessment and a fresh perspective for examining the impact of media literacy on cultivating complex, critical thinking skills that could be applied with learners of all ages.
\end{abstract}

Keywords: media literacy, assessment, inquiry, effectiveness, media literacy education, higher education

Media literacy is a field of study with over fifty years of history in the United States, yet it has only recently become a focus of national attention. With the surge of "fake news" in past years, media literacy has been suggested as a possible strategy in addressing the problems of misinformation. A well-cited study by Wineburg, McGrew, Breakstone, and Ortega (2016) shocked audiences with the conclusion that school-aged students were unable to differentiate between false and legitimate information. They cautioned: "whether [the Internet] will make us smarter and better informed or more ignorant and narrow-minded will depend on 
our awareness of this problem and our educational response to it" (Wineburg et al., 2016, p. 5). As an educational response positioned to address such gaps, media literacy is garnering wider interest and support.

Defined as "the ability to access, analyze, evaluate, create, and act using all forms of communication" (National Association for Media Literacy Education [NAMLE], n.d., para. 1), media literacy embodies a contemporary response to the preparation needed for people of all ages to engage actively and effectively in the digital world. Growing interest in media literacy has prompted legislation to advance its inclusion in U.S. schools, specifically pertaining to digital citizenship, news literacy, and information literacy (Media Literacy Now, n.d.). For the media literacy community, we are energized and appreciative of overdue attention to core literacy concerns related to our democracy. Yet, as we seek to grow practice, questions about breadth and impact arise. How do we know if media literacy works? What do media literacy skills look like in action? While decades of scholarship have established consistent concepts (NAMLE, 2007) that serve to define media literacy principles, unified efforts for assessing the media literacy of people at all ages are needed. Without a comprehensive approach or clear metrics through which to evaluate the outcomes of media literacy, implementation and action may struggle. The absence of structured assessment procedures have likely contributed to the lack of status afforded to media literacy in the past (Buckingham \& Domaille, 2009, p. 26).

Many scholars have worked to amend the gap in evaluation through the development of assessment instruments and testing measures using both empirical and quasi-experimental studies (e.g., Arke \& Primack, 2009; Chang \& Lui, 2011; Duran, Yousman, Walsh, \& Longshore, 2008; EAVI, 2010, 2011; Hobbs \& Frost, 1998, 2003; Inan \& Temur, 2012; Maksl, Ashley, \& Craft, 2015; Primack et al., 2006; Primack, Sidani, Carroll, \& Fine, 2009; Quin \& McMahon, 1995; UNESCO, 2013; Vraga, Tully, Kotcher, Smithson, \& Broeckelman-Post, 2015; Worsnop, 1996; Wulff, 1997). In these measures, the participants - usually students - provide answers to researcher-generated questions. Yet, as critical inquiry lies at the heart of media literacy, examining students' abilities to ask their own questions may offer fresh insights into the potential of media literacy practice to improve students' critical thinking. In turn, our study facilitates new directions in media literacy assessment by flipping previous research approaches in order to examine changes in people's media literacy skills as represented by the questions they themselves pose before and after media literacy learning. Through data collection and analysis of participants' questions about a media sample before and after a course in media literacy, we evaluated changes in both the concepts that students focused on in their questioning and the complexity of their questions. Our study addresses the following four research questions:

RQ1: What key concepts do students ask questions about before taking a media literacy course?

RQ2: What is the complexity of students' questions before taking a media literacy course? 
RQ3: To what extent is there a difference in the frequency of concepts students ask questions about before and after they take a media literacy course?

RQ4: To what extent is there a difference in the complexity of the questions students ask before and after they take a media literacy course?

\section{REVIEW OF LITERATURE}

\section{Media Literacy Assessment Measures}

Assessment in media literacy inquiry may generally be comprised by either a competency-based or self-assessment approach (Hobbs, 2017a). For instance, Quin and McMahon (1995) evaluated two competency-based media literacy tests developed by a panel of teachers. In both tests, students examined language, narrative, audience, and other areas of media analysis. Another example of a competency-based assessment was developed by Hobbs and Frost (2003) in which they tested 11th grade English Language Arts students' reading comprehension, writing skills, critical reading, critical listening, and critical viewing skills for nonfiction informational messages. Duran et al. (2008) used a competency-based approach where participants answered three open-ended questions generated by the research team about an advertisement. Finally, Arke and Primack (2009) used quantitative scales based on an underlying conceptual model to evaluate competencies.

Together, competency-based approaches contrast with self-assessment approaches where participants rate their own media literacy knowledge, skills, or attitudes. Self-assessments typically move beyond cognitive approaches to deal with values. For example, Primack et al. $(2006,2009)$ focused on media literacy as an intervention to curb smoking. Chang and Lui (2011) developed a media literacy self-assessment scale (MLSS) for students, whereas Inan and Temur (2012) created an assessment instrument to examine media literacy levels of prospective teachers. More recently, UNESCO (2013) developed an assessment framework in which teachers are asked to rate their own skills and competencies as well on a global scale.

Encouraging continued studies, Martens (2010) and Hobbs (2017a) have both emphasized the urgency of more reliable research instruments to "aptly capture media learning outcomes" (Martens, 2010, p. 15). Martens (2010), in particular, questions whether many of the results of experimental research generalize to everyday media use, suggesting that new research aim should be focused on capturing the long-term influence of media literacy on individuals' daily life (Martens, 2010). Further, researchers should examine whether the skills learned by media literacy education transfer to new situations (Schilder, Lockee, \& Saxon, 2016). Our study addresses existing gaps in two ways: (1) it is an example of a student-centered approach to media literacy evaluation, and (2) it seeks to simulate everyday media use by capturing the inquiries of people when viewing media. 


\section{Inquiry-Based Learning and Questioning}

Media literacy encompasses a range of skills, but our study emphasizes assessment of inquiry. Inquiry learning is defined by Kuhn, Black, Keselman, and Kaplan (2000) as "an educational activity in which students individually or collectively investigate a set of phenomena-virtual or real-and draw conclusions about it" (pp. 496-497). In developing habits of inquiry, practitioners teach students to ask "specific types of questions that will allow them to gain a deeper or more sophisticated understanding of media messages" (NAMLE, 2007, p. 3) and many scholars and organizations have defined central questions for teaching media literacy (Bazalgette, 1989; Buckingham, 2003; Duncan, D’Ippolito, Macpherson, \& Wilson, 1998; Mihailidis, 2014; NAMLE, 2014; Thoman, n.d.). Inquiry models are largely characterized by open-ended questions where the questioner actively negotiates both messages and meanings. For example, the questioner may ask: "Why might this message matter to me? What kinds of actions might I take in response to this message? Why were these techniques used?" (NAMLE, 2014, p. 1). Examples of inquiry approaches include: The Center for Media Literacy's (CML) "Five key questions of media literacy" (2011), The Text Audience Production (TAP) model (Duncan et al., 1998), and NAMLE's "Key questions to ask when analyzing media messages" (NAMLE, 2014). Other models for inquiry include scholarly frames from Bazalgette (1989) - who suggested asking questions about agencies, categories, technologies, languages, audiences, and representation-and Buckingham (2003) who created questions related to production, language, representation, and audiences (Schilder, 2014). Through open questioning, audiences are primed to engage in active inquiry about the myriad messages they consume and create and to negotiate meaning across the contexts of information and communication technologies.

\section{Grounding in Key Concepts}

While the key questions of media literacy represent the active processes of inquiry, they are grounded in funds of knowledge developed through media literacy learning. In this way, media literacy education teaches people to ask questions about specific domains, or concepts, allowing them to gain a more sophisticated understanding of the nuances of mediated communications. For example, people might learn to ask questions about "authors and audiences," "messages and meanings," and "representations and reality" (NAMLE, 2014). Some historical models identify essential concept areas in a single title that may be coupled with questions, such as "text, audience, and production" (Duncan et al., 1998) or "production, language, representation, and audiences" (Buckingham, 2003). Other models provide a statement that denotes the key concept or idea, such as "media messages are constructed," "media contain and convey values and ideologies," and "audiences negotiate meaning" (e.g., Considine \& Haley, 1999; Hobbs, 2017b; Share, Jolls, \& Thoman, 2005). While a complete review of concepts is beyond the scope of this piece, readers are encouraged to refer to our review of conceptual models in a previous publication (Redmond, Schilder, \& Moore, 2016).

What is essential to understand is that these conceptual models help audiences develop domains of knowledge related to mediated communications that 
they may use to extend learning outside of the classroom. Consistency between existing media literacy models and frameworks internationally lends substantive value to these concepts collectively (Redmond et al., 2016). Ultimately, as Masterman (1985) explains, structures in media literacy education are not exhaustive and instructors may adapt concepts to fit a range of content areas and objectives. The purpose of cultivating knowledge of these key concepts through open-ended questioning is to help people develop healthy habits of inquiry where they regularly ask these questions themselves, even after they leave the learning context. In our study, we investigate media literacy inquiry among college-aged students, examining which concepts students ask questions about before taking a media literacy course and how the frequency of asking questions about those concepts changes afterwards.

\section{Complexity and Higher Order Thinking}

Beyond key concepts, our study examines new areas relevant to the realms of critical thinking. Because a goal of media literacy education is to develop critical habits of mind that transcend the classroom in order to be relevant during media engagement throughout life, it is important that people not only build funds of knowledge, but also mental habits to extend those funds of knowledge to new media. In this regard, our study aims to examine to what extent is there a difference in the complexity of the questions students ask before and after they take a media literacy course.

Traditionally, complex and abstract thinking skills are referred to as higher order thinking skills and these skills — such as the ability to analyze, evaluate, and create media messages - are a focal point in media literacy education. Although Bloom, Engelhart, Furst, Hill, and Krathwohl (1956) did not specifically define higher order thinking in their Taxonomy of Educational Objectives, much of the writing on higher order thinking referenced their classification within the cognitive domain, suggesting movement from knowledge to evaluation as signifying a progression from lower to higher order thinking (Alexander et al., 2011). Many scholars acknowledge the complexity involved in higher order thinking and the transformative nature of students moving from knowledge levels in recall and comprehension to advanced synthesis and evaluation (Schilder, 2014). Lewis and Smith (1993) assert that "higher order thinking occurs when a person takes new information and information stored in memory and interrelates and/or rearranges and extends this information to achieve a purpose or find possible answers in perplexing situations" (p. 136). This broad, encompassing conception includes problem solving, critical thinking, creative thinking, and decision making (Lewis \& Smith, 1993). Schraw and Robinson (2011) defined higher order thinking as "skills that enhance the construction of deeper, conceptually-driven understanding" (p. 2). Alexander et al. (2011) add to this by explaining "the mental engagement with ideas, objects, and situations in an analogical, elaborative, inductive, deductive, and otherwise transformational matter that is indicative of an orientation toward knowing as a complex, effortful, generative, evidence-seeking, and reflective enterprise" (p. 53). While there is ample literature related to higher order 
thinking, we have not identified literature suggesting complexity as a focus in media literacy assessment.

\section{METHODOLOGY}

\section{Research Context and Participants}

The participants were 72 undergraduate students at a large, public university in the southeastern United States who were enrolled in a semester long media literacy course. We gathered data over two semesters (Fall 2014 and Spring 2015) using two different courses, including multiple sections of one course, with each course section comprising about twenty students. The first class was a required teacher education course focused on "how emerging technologies are transforming our society and schools [and] the implications these changes have for teaching and learning" intended to help students develop "strategies for building critical habits of mind with respect to new technologies" (Appalachian State University, 2014). The second class was a media literacy course involving students from Communications, Journalism, Advertising, and Broadcasting. In this class, students "examine[d] what it means to be literate in the technological world of the twentyfirst century" with a focus on "understanding media texts, media industries, media narratives, and the form and language of a variety of different media" (Appalachian State University, 2015). Student demographics were consistent with the overall demographics of the university comprising: mostly female, Caucasian, American born, in-state residents, between the ages of 18-21 years old. All 72 student participants completed both the pre-and-post surveys, contributing to a data pool of 704 combined pre-and-posttest questions. They asked 328 questions in the pretest and 376 questions in the posttest.

\section{Research Design}

To assess students' questions, we employed a pretest-posttest experimental design. In the pretest, the participants viewed a commercial media sample from the 2013 Super Bowl entitled Busloads of kids get surprise trip to Toys R Us (Heine, 2013). The advertisement depicts a busload of children on their way to a nature field trip portrayed as boring. To their surprise, they are taken to Toys R Us instead and the remainder of the commercial illuminates their enthusiasm.

We selected this advertisement as a rich media sample that could be interpreted in multiple ways, making it accessible for a range of audiences. The ad employs many production techniques, including narrative, camera language, props, music, and interviews. Further, its circulation during the 2013 Super Bowl was an important criterion due to increased viewership. Viewer response at the time of dissemination was mixed, as the story contains implicit and ideological messages positioning children to value consumerism over nature. Participants could view the advertisement multiple times as it was linked in the survey.

The survey prompt invited students to consider questions that arose while viewing the advertisement. Specifically, we asked: "For this activity, please watch the media provided. While you are watching, analyze the media. What questions come to mind while you watch this media? List your questions here. You can list 
as many or as few questions as you feel are necessary. Please number your questions." Following viewing the ad, students typed up the questions they thought of while viewing in an open text field. Next, students took the semester long media literacy course. At the end of the course, students were asked to watch the media sample again and to respond in the survey. There was no set time limit for students to come up with their responses.

\section{Instrument Development}

To organize and analyze students' questions, we developed two codebooks, one for media literacy concepts and a second for complexity level. Using the process described by DeCuir-Gunby, Marshall, and McCulloch (2011), we articulated three basic dimensions for each codebook: (1) code name, (2) full definition (an extensive definition that collapses inclusion and exclusion criteria), and (3) example questions. We developed our codebooks through many rounds of data analysis, including: an initial phase using a small sample of 18 students' combined pre-and-post test questions with an a priori coding approach, a second phase using a larger sample of 59 participants' pre-and-post surveys with an open coding approach, and multiple phases of iteration and refinement with a focus on achieving interrater reliability and a stable metric. Identifying the Biggs and Collis' (1982) SOLO Taxonomy through research by Rickles, Schneider, Slusser, Williams, and Zipp (2013) represented the crux of refining our complexity codebook and, ultimately, our adaptation and application of the SOLO Taxonomy provided a strong metric to gain insight into the specific aspects of students' questions that make them more or less complex.

An acronym for the Structure of Observed Learning Outcomes, Biggs and Collis' (1982) SOLO Taxonomy provides an opportunity to investigate the nuances of thinking and disarticulate aspects that make thinking more or less complex. Initially developed to classify student learning outcomes in terms of quality, Biggs and Collis' (1982) work has been taken up by assessment and curriculum design circles (Biggs \& Tang, 2011; Ramsden, 1992), in addition to those interested in evaluating changes in critical thinking (Rickles et al., 2013). Based on research that examined student learning, the taxonomy includes five hierarchical outcomes that indicate the complexity of students' understandings. Ranging from prestructural, where no understanding is suggested, to extended abstract, where learners demonstrate understanding in a way that surpasses the initial scope of inquiry, the SOLO Taxonomy offers our research insight into addressing the interconnectedness of key media literacy ideas and concepts, such as how production techniques may impact or shape reception among audiences (Redmond et al., 2016).

Working with the five hierarchical outcomes of the SOLO Taxonomy in conjunction with Bloom's Taxonomy, we remixed new codes to classify students' questions in terms of lower or higher order thinking, fleshing out the particular nuances of their thinking with the structural levels from Biggs and Collis (1982). Specifically, our codebook for complexity is transformational in that we applied the existing SOLO Taxonomy to focus not on learning objectives, but rather on 
questions, ultimately blending their structure with a focus on mental tasks from Bloom's Taxonomy.

\section{Validity and Reliability}

We enhanced the validity of our codebooks with attention to media literacy literature for the key concepts and using the Bloom's and SOLO Taxonomies to develop measures for complexity. To further establish rigor and validity for our code book for concept, we invited a third expert to join our research team during the development process and, following multiple rounds of coding, scored a Cohen's Kappa of 0.604, establishing a data-driven and reliable metric for organizing students' questions by concept. We later improved upon this score as a team of two researchers, establishing interrater reliability for both codebooks using Krippendorff's alpha coefficient (Krippendorff, 2004) as all data was ordinal. The interrater reliability for concept was 0.915 and the interrater reliability for complexity was 0.811 (Krippendorff's alpha coefficient). To further develop the efficacy of our codes, we queried three professional scholars in the field of media literacy in the United States, soliciting an expert review of our codebook in October 2017. One scholar responded with thoughtful feedback that we were able to incorporate into our revision process to further enhance its validity.

Through each stage of the research process, we minimized validity and reliability threats through myriad strategies, including using a consistent research prompt, media sample, and codebook in both the pretest and the posttest. While the study was purposefully conducted this way to minimize any forms of bias, a pretestposttest approach generally has the potential to create a testing effect. This may be evident in our study as students viewed the same advertisement before and after the course. To mitigate potential testing effects, we took two precautions. First, during the pretest-posttest, participants were permitted to view the media sample as many times as needed. Second, there was no time limit for participants to generate questions about the media sample, enabling them to think deeply about the media sample. By not setting a time limit and giving the opportunity to view the advertisement multiple times, we limited possible testing effects.

\section{Instrumentation}

Concept. Our codebook for concept features seven codes: Purpose, Text, Production, Audience, Representations, Realism, and Not Critical. Six codes align well with established, historical frameworks in media literacy education: purpose, text, production, audience, representations, and realism. These categories reflect students' developing funds of knowledge in media literacy or actual areas of questioning related to media or concepts. For example, questions aligned with Code 1 "Purpose" focused on the objectives of the message, including aspects related to authorship, context of dissemination, and economics. These questions largely elicit information about why the message was created and disseminated, when and how, by whom, and other inquiries about the general intentions of the media sample. Yet, for Code 7 "Not Critical," questions did not reflect media literacy concepts as funds of knowledge. Instead, they reflected a developmental process of learning to actually question media. Questions coded in this way were about process, not 
content. Questions in Code 7 "Not Critical" encompassed a range of unclear questions, including misconceptions (e.g., What reasons do you think Toys R Us might have had in organizing the trip?) or questions that suggested the student did not grasp the constructedness of the media (e.g., Is this an event that happens often?).

Complexity. Our codebook for question complexity features five codes, ranging from lower order thinking with Code 0 at the prestructural level to higher order thinking with Codes, 2, 3, and 4. These were: Not Critical/Prestructural, Low/Unistructural, High/Multistructural, High/Relational, and High/Extended Abstract. We distinguish between closed and open-ended questions as indicators for evidence. For instance, Code 1 is a lower order categorization at the unistructural level where questions tend to focus on one piece of basic or fixed information that is readily identifiable within the media sample. Questions in this category require lower order mental tasks according to Bloom's Taxonomy, including recalling, listing, naming, and describing. Because they focus on precise information that resides within the media sample as a text, these questions tend to be closed and do not require evidence to back up responses. For example, the questions "What was used to film this?" and "What were the reactions of most of the students?" convey unistructural, lower order thinking skills.

In contrast, the three higher order thinking levels (Code 2, Code 3, and Code 4) are differentiated based on relationships between components of the media sample or concepts of media literacy addressed in students' questions, in conjunction with the evidence required by their inquiries. For example, Code 3 is a higher order thinking category at the relational level where students' questions focus on breaking down main ideas and information with attention to the connections or relationships between concepts. The mental tasks involved require higher order skills, such as analyzing to determine relationships and synthesizing ideas. These questions generally focus on multiple dimensions or aspects as conceptually integrated and may require evidence. For instance, the question "Why do you think the producer chose to use such bright colors in this video?" refers to the interconnectedness of multiple concepts of media literacy, including purpose, text, and production techniques. Responding to this question requires the answerer or audience to have an awareness of these multiple concepts as they exist in relationship to each other, in addition to evidence, as the "Why" question stem is open-ended. Another example is "Why were they more excited about toys than about a nature park?" As an open-ended question, this inquiry also requires evidence related to the narrative of the media sample in conjunction with its commercial purpose. The codebooks are provided in the Appendix.

\section{Data Collection}

Participants entered their questions using online software called Select Survey. Questions were linked to the participants and entered into Excel to be coded. After interrater reliability was established, each researcher coded half of the data. Pre-and-posttest questions were mixed to prevent any bias when coding.

Coding for concept. In coding for concept, we realized each question could be coded for multiple categories. For example, the question "What are some media 
techniques used in creating this video that helped keep you (the audience) engaged?" addresses both "production" and "audience" as it contained elements tied to both concepts. In turn, this question was coded for both Code 3 and Code 4 . Multiple codes per question were weighted based on importance. For example, if one question was coded in four different categories, the code that was most prominent was coded as $100 \%(1)$, the second $75 \%(0.75)$, the third $50 \%(0.5)$ and the fourth $25 \%(0.25)$. Questions that were coded as "not critical" could not fall into any other category, however, as these questions did not demonstrate any level of media literacy knowledge.

Coding for complexity. In coding for complexity, each question was coded on a scale from zero to four, where zero represented the "not critical, prestructural category," and four represented the "extended abstract" category. A complexity question could only be coded for a single category.

\section{Data Analysis}

We analyzed data using SPSS software. To answer the first two research questions, we calculated frequencies. In order to measure the differences between students' questions before and after taking the media literacy course, we ran pairedsample t-tests separately for each of the concepts and for complexity.

\section{FINDINGS}

\section{RQ1: What key concepts do students ask questions about before taking a media literacy course?}

Before taking the media literacy course, most inquiries, a total of 84 questions $(25.6 \%)$, were related to audience. These are questions that focus on who the audience is in general terms, in addition to eliciting information about the experiences, interpretations, emotions, or opinions of the viewers/audiences of the media sample, including their subsequent feelings, physical responses, and actions. The next category that most questions fell into was the not critical category (72 questions; 22.0\%). These are the questions that were unclear, reflected misconceptions, did not answer the research prompt, or demonstrated that the questioner did not grasp the constructed nature of the media sample.

Students addressed the concept of purpose in 66 questions (20.1\%), focusing on the objective of the message, including aspects related to authorship, context of dissemination, and economics. Questions were related to media production in 66 cases $(20.12 \%)$. These questions focus on how the media was constructed, what production techniques were used, and why these techniques were used. In 64 questions (19.5\%), students referred to aspects of the media text itself. These questions focus on the explicit content of the text as a narrative, encompassing what was happening and who was involved.

Students asked relatively fewer questions related to realism and representation. Only 39 questions $(11.9 \%)$ were related to representation. Representation questions focus on the implicit content of the text and issues related to stereotypes, ideologies, and socio-political and cultural values. A total of 27 questions $(8.2 \%)$ related to realism. These questions focus on eliciting information 
about the constructedness of the media, specifically prompting the answerer to critically consider the nature of the media in terms of reality. Figure 1 shows the number of questions students asked related to key concepts before taking the media literacy course.

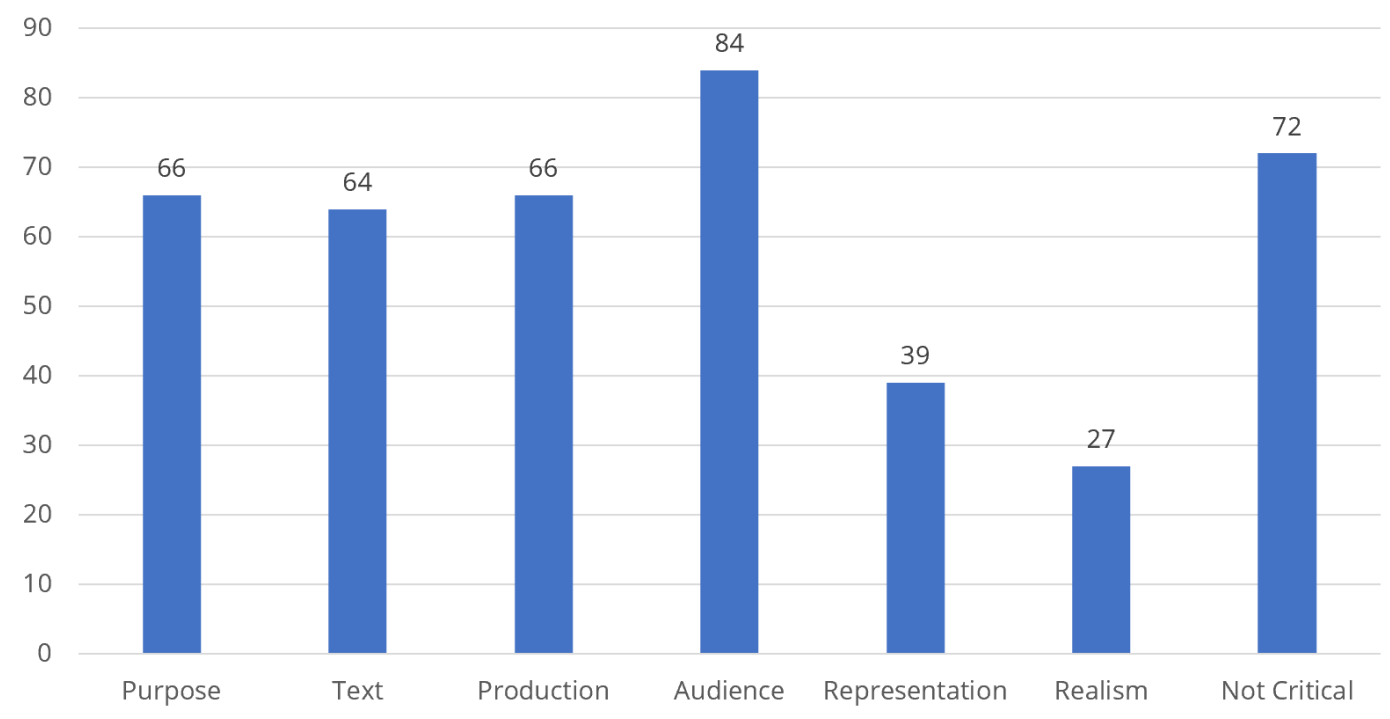

Figure 1. The concepts students asked questions about before taking the media literacy course

\section{RQ2: What is the complexity of students' questions about media before taking a media literacy course?}

Out of the 328 questions students asked in the pretest, 72 were not critical questions $(22 \%)$. The not critical code carried over into our analysis of question complexity in this way, defined as prestructural.

Students asked 20 questions that fell into the unistructural category (6.1\%). These are questions that only focus on one piece of basic or fixed information that can easily be identified or recalled from the text. An example is: "What type of media is this?"

Comparatively, most questions fell in the multistructural category. A total of 147 questions fell into this category $(44.8 \%)$. These are questions that focus on breaking down main ideas and information, but do not examine relationships or require evidence-based thinking. An example would be: "How does this clip make you feel?"

Students asked 62 questions $(19.2 \%)$ that fell into the relational category. In this category, students analyze the relationships of multiple concepts and typically reflect evidence-based thinking (e.g., asking "how" and "why" questions). An example would be: "Why do you think the producer chose to use such bright colors in this video?"

Finally, 26 questions were classified as extended abstract questions (7.9\%). This category reflects the highest level of complexity. These were questions that focus on extending ideas and information into other domains or contexts in new ways - connecting, synthesizing, and transforming. An example is: "What 
messages does this video send about American ideals?" Figure 2 shows the complexity of students' questions before taking the media literacy course.

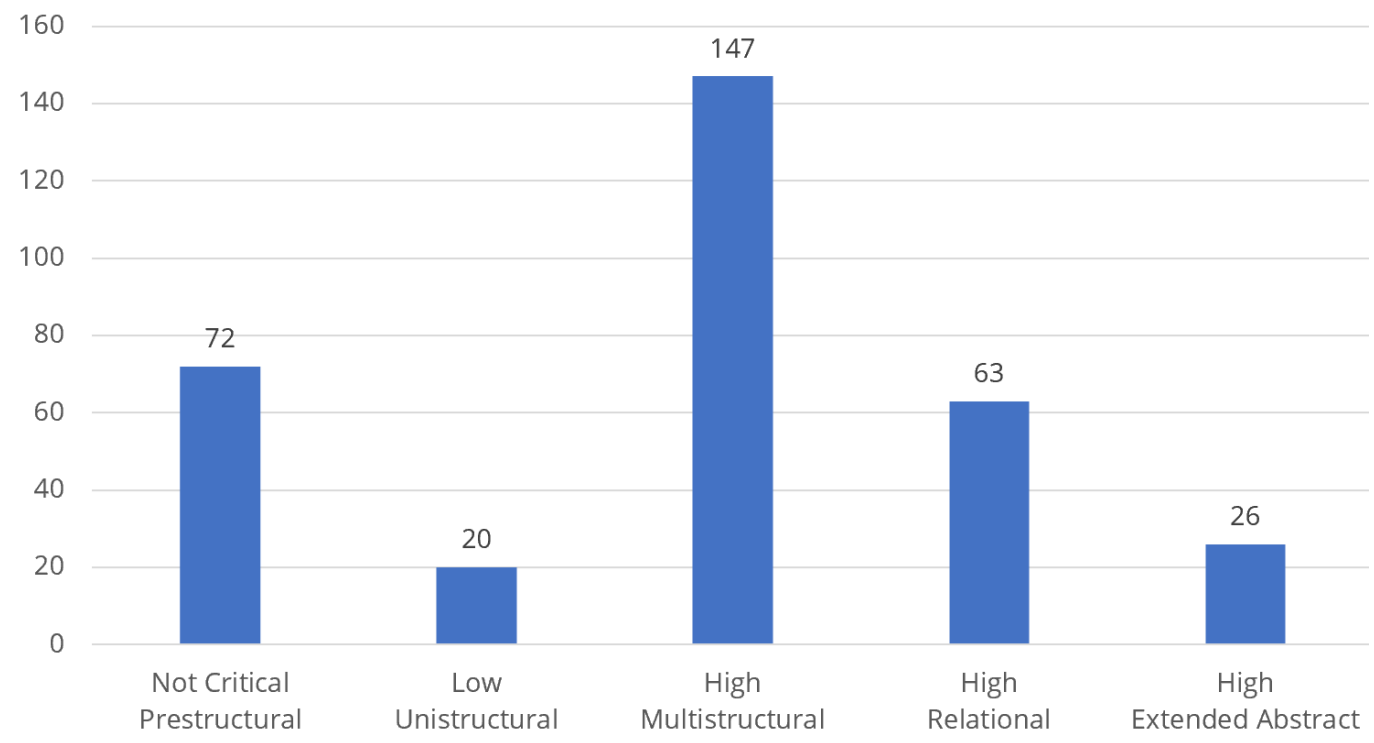

Figure 2. The level of complexity of the questions students asked before taking a media literacy course.

RQ3: To what extent is there a difference in the (frequency of) concepts students ask questions about before and after they take a media literacy course?

For each of the six concepts and the not critical category, we ran a paired sample t-test to compare students' questions before and after taking the media

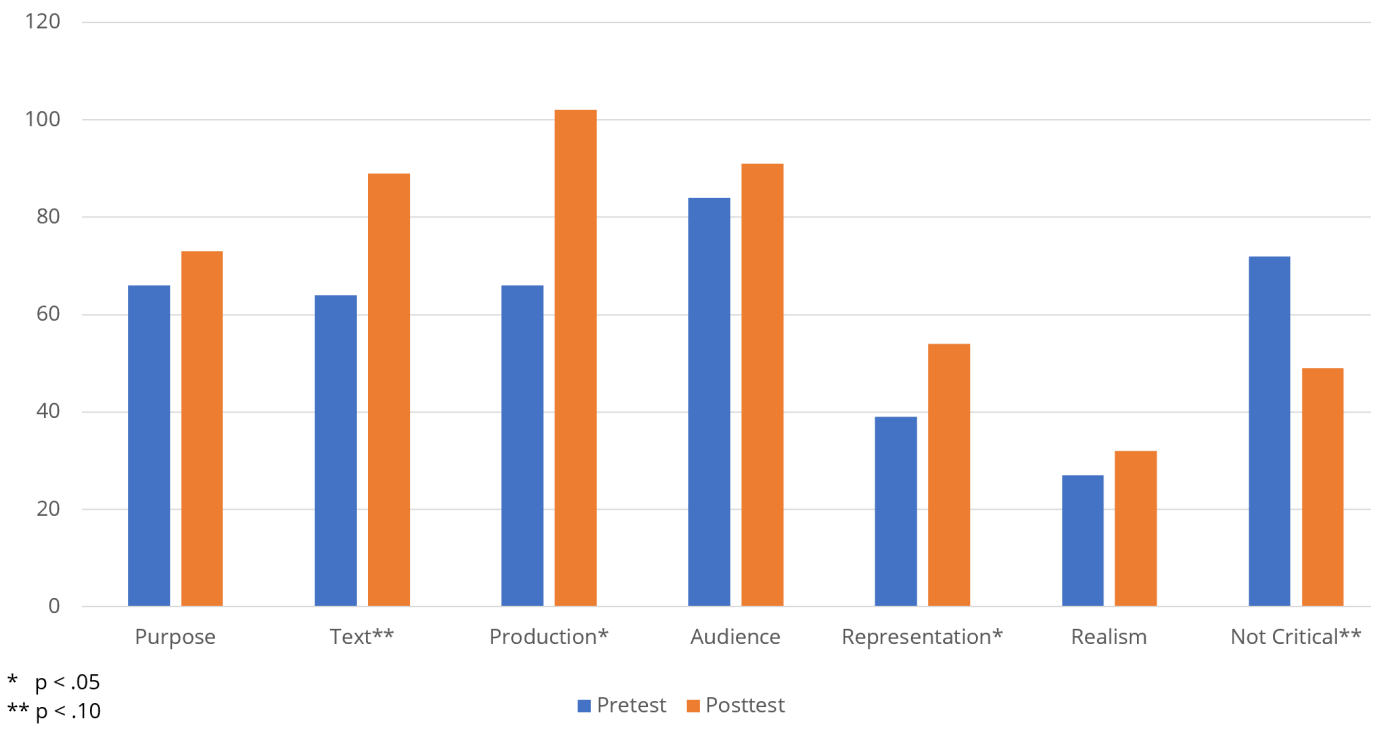

Figure 3. The differences in the frequency of concepts students asked about before and after taking the media literacy course 
literacy course. The differences in the frequency of concepts students asked about before and after taking the media literacy course are provided in Figure 3.

After students took the course, they asked significantly more production questions $(M=1.22, S D=1.64)$ and representation questions $(M=0.75, S D=1.11)$ compared to prior the course (production: $M=0.81, S D=1.17), t(71)=-1.99, p=$ 0.05 ; representations: $M=0.44, S D=0.74), t(71)=-2.27, p=0.03)$.

Furthermore, results indicated a marginally significant increase in questions about text after the course $(M=1.03, S D=1.15)$ compared to prior the course $(M$ $=0.76, S D=0.89) \mathrm{t}(71)=-1.78, \mathrm{p}=0.08$. The results for the not critical category were marginally significant as well. Unlike the other categories, students tended to ask less "not critical" questions after they took the course $(M=0.68, S D=1.29)$ in comparison to before the course $(M=1.00, \mathrm{SD}=1.61), t(71)=1.17, p=0.10$.

Finally, the findings indicated that there was not a significant difference between the amount of questions students asked before taking the course about purpose $(M=0.77, S D=1.09)$, audience $(M=1.04, S D=1.41)$, and realism $(M=$ $0.35, S D=0.73$ ) compared to after taking the course (purpose: $M=0.86, S D=$ $1.00), t(71)=-0.59, p=0.56$ ); (audience: $M=1.15, S D=1.08), t(71)=-0.58, p=$ $0.57)$; (realism: $M=0.42, S D=1.16), t(71)=-0.47, p=0.64)$.

\section{RQ4: To what extent is there a difference in the complexity of the questions students ask before and after they take a media literacy course?}

We conducted a paired sample t-test to compare the complexity of students questions before and after taking the media literacy course. The findings indicated that students asked significantly more complex questions after taking the course $(M$ $=2.17, S D=0.86)$ compared to before taking the course $(M=1.94, S D=0.91)$, $t(71)=-2.01, p=0.05)$. The differences in the frequency of questions asked for each level of complexity are displayed in Figure 4. It is especially interesting to note the considerable increase of relational questions after students took the media literacy course (140 in the posttest compared to 63 in the pretest).

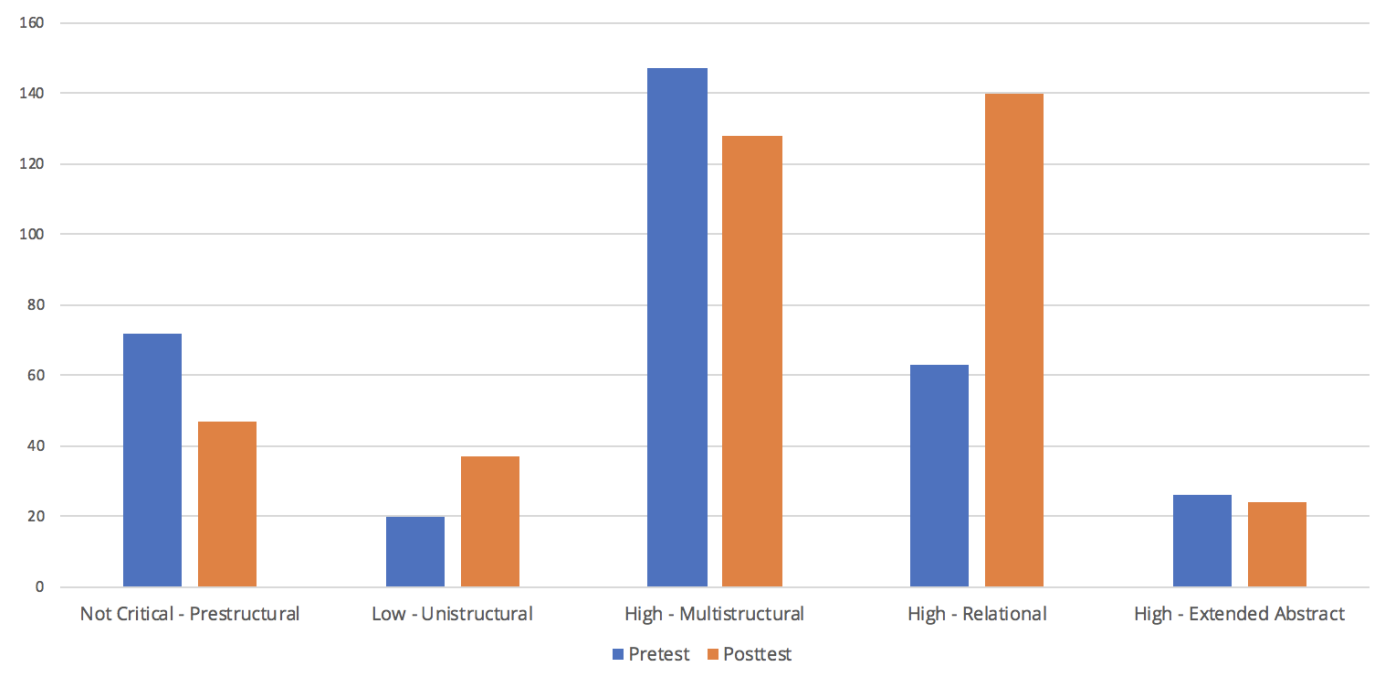

Figure 4. The differences in the levels of complexity of student questions before and after taking the media literacy course. 


\section{DISCUSSION}

\section{Learning to See Beyond the Story}

We found a significant increase in media literacy questions related to production techniques. Production techniques focus on how media were constructed, what production strategies or appeals were used - such as lighting, music, framing, camera language, and other audio-visual elements - and why these techniques were used. Examples of student questions related to media production include: "What might have been the purpose to providing close-up shots of the children holding and playing with their toys?" and "What are some media techniques used in creating this video that helped keep you (the audience) engaged?"

An increase in questions related to production is important because it conveys that students develop skills to detect that media construct reality. Increasingly, we are immersed in media that appear to be part of our natural world. Yet, while media messages seem real, they are carefully crafted texts that leverage a range of production techniques that often bypass our cognitive and critical thinking. We may only become aware of the constructedness of media messages by deconstructing them. Stepping back to consider how media messages are created, what media production techniques are used, and how these production techniques may influence us are crucial inquiry skills. Hence, the increase in these types of questions is an important finding that suggests media literacy education facilitates people engaging in critical inquiry into how messages make meaning. Ultimately, the increase in questions related to production techniques shows that media literacy education may lead to students and society becoming less susceptible to the potential influence of particularly manipulative propaganda that could impact our democracy at large. Finally, a substantial increase in students' abilities to ask questions about production techniques may also have implications for their abilities to create high quality media as part of a participatory culture (Jenkins, Purushotma, Weigel, Clinton, \& Robison, 2009).

\section{Learning to Engage in Social Justice}

We found that students asked significantly more questions about representation. We classified questions related to representations as inquiries that focused on issues related to stereotyping, agenda, bias, ideologies, and sociocultural values. Representations questions provided an entry for the answerer to consider how media impact social norms and cultures, including conceptions of gender, race, ethnicity, and sexuality. For example, after taking a media literacy class, students asked questions like: "How does this video represent race?" and "What does it mean that children are eager to contribute to consumerism but aren't interested in nature knowledge?" Our findings indicate that media literacy has the potential to expand students' awareness, recognition, and abilities to articulate how values or ideologies contained in media messages may impact people and policies. These findings are aligned with the suggestion by many scholars that media literacy comprises an emancipatory practice (Cortés, 2000; Hobbs \& Frost, 1998) that has 
implications for sustaining democratic practice (Kellner \& Share, 2005, 2007; Torres \& Mercado, 2006).

\section{Learning to Think Deeply}

We found that students asked more complex questions after they took the media literacy course. These findings indicate that media literacy education is successful in not only cultivating students' critical thinking in terms of the funds of knowledge students have about media messages, or the concept areas they ask questions about, but also in expanding the depth and complexity of their thinking. For example, they asked more relational questions, examining the interconnectedness between concepts, such as the possible influence of specific production techniques on audience interpretation. The ability to ask higher level questions about media messages and the ability to ask questions about the relationships between various concepts can help people become more active agents when interacting with media. They are challenged to think at a deeper level about the ways media messages are created and how media may influence us in all aspects of our lives. Ultimately, asking more complex questions can help people become better at critically analyzing and evaluating media messages, which are key purposes of media literacy education.

\section{Learning to Inquire}

After taking a course in media literacy, there was a marginally significant decrease in the amount of "not critical" questions students asked compared to the questions they were able to generate before media literacy learning. We classified "not critical" questions as those inquiries that were unclear, did not address the research prompt, reflected misconceptions, or generally suggested that students did not understand the constructedness of the media. Before taking the media literacy course, numerous students were not aware of the commercial intent of the media message. Their questions suggested confusion about whether they were watching an advertisement or if the story was showing a real event that Toys R Us organized. It was a positive outcome to find that students asked less "not critical" questions in the posttest. This indicates that media literacy education is effective in cultivating critical media inquiry for students coming into the course with no or limited prior knowledge or inquiry structures for critically analyzing media messages and that it prepares these students with the ability to decode media texts. Our findings relate to research suggesting that media literacy education has no or limited presence in traditional public K-12 education systems. Indeed, existing scholarship of media literacy in K-12 settings comprises a smattering of case studies that reveal media literacy is rarely included and, when it is integrated, it is added on to the curriculum as an extra, temporary course sequence (Redmond, 2012) or included as a special, grant-funded or other research-initiative (Hobbs, 2007; Kist, 2005; Share, 2009). A further implication of our finding suggests not only a lack of media literacy learning in students' K-12 experiences, but also a gap in teacher education programs and training. In order for media literacy to become a foundational aspect of literacy instruction and praxis in K-12 education, it must first be a formalized aspect of 
media literacy curricula in teacher education courses or programs (Redmond, 2016; Schilder et al., 2016; Schmidt, 2013).

Related to a decrease in students" "not critical" questions was a marginally significant increase in media literacy inquiry about the media message as a text overall. Our findings showed that students seemed to be paying better and more focused attention to the media as a text that contains and conveys meaning, asking more questions that focused on the explicit content or narrative of the media sample, such as what was happening and who was involved. This finding suggests that media literacy may contribute to students' active viewing of media messages, which may be a crucial prerequisite for deeper media literacy learning.

\section{IMPLICATIONS FOR FUTURE RESEARCH}

Our study is the first of its kind to explore habits of inquiry in media literacy education in terms of funds of knowledge and the complexity of thinking. There are still many unexplored avenues and there are several recommendations for further research that may benefit the fields of digital, information, and media literacy. We recommend future studies include a control group to determine the impact of the test-retest effect. This will give insight to whether exposure to the same prompt at different times may influence the questions students ask or how they ask questions.

Moreover, although our sample was robust, we recommend future studies collect a larger sample of questions so it is possible to examine the level of complexity of questions within each of the concepts explicitly. This would allow researchers to determine if students not only ask more questions about representation after taking a media literacy course, but also whether the questions about representation are significantly more complex questions. In other words, examining the complexity levels within concept areas may offer insight into how key concepts in media literacy may be inherently connected to deeper inquiries.

Furthermore, it is crucial to keep refining any research design and data analysis process. For this study, the way questions are coded and weighted impact the findings. We recommend scholars examine varied methods to weigh the coded data. Additionally, we urge investigators to consider whether and how the codebook may be used with other media samples and prompts. For example, in our study, we employed an advertisement as the media sample. Yet, how might student inquiry be different if the media sample was a photograph? A news article? A Tweet? As McLuhan and Fiore (1967) note, "the medium is the message" and we wonder if the medium of the sample could impact not only message, but also inquiry.

Finally, we would like to offer a friendly warning to researchers seeking to measure and evaluate media literacy learning. The danger of assessment in media literacy is that we reduce complex, critical inquiry to a set of unidimensional competencies, and, in doing so, eliminate foundational dimensions of effective media literacy pedagogy. How can we preserve the critical integrity of inquiry in assessment? In considering how to measure media literacy without constraining students to pre-determined assumptions or defined knowledge, we recommend researchers incorporate a social-constructivist praxis and attend to the broader, 
value-based implications of media literacy. Audiences negotiate meaning and the power of inquiry resides largely in the invitation for learners to actively engage and grow as learners from and through all backgrounds, experiences, and knowledge bases. To this end, research into the dispositions developed by the Association for College and Research Libraries in their Framework for Information Literacy in Higher Education (American Library Association, 2015) may be fruitful. We also discourage the use of self-assessment measures. While these instruments are easy to use with larger groups of research participants, they are more often a measure of people's confidence surrounding their use of media rather than a valid assessment of their habits of inquiry and ability to critically analyze, evaluate, and create media messages (Schilder et al., 2016).

\section{CONCLUSION}

Our study represents an innovative approach for evaluating the effectiveness of media literacy inquiry that is greatly needed as we embark deeper into the complex information ecologies and economies of the twenty-first century. By investigating changes in people's habits of inquiry in media literacy in terms of their funds of knowledge and the complexity of their thinking, we have been able to demonstrate that media literacy is effective in cultivating critical and complex thinking. Most importantly, our study is significant because it demonstrates that media literacy goes beyond a set of concrete and stagnant digital competencies. Instead, media literacy education is an active, dynamic process of complex thinking grounded in critical inquiry. Media literacy is not a noun, or something you have, but rather a verb; it is something you do! Media literacy works to develop audiences' awareness and abilities to decode key areas of message construction, dissemination, and effects. Through media literacy learning, people of all ages may not only cultivate more funds of knowledge related to core concepts in media, but also higher order, complex thinking skills that represent their abilities to relate, connect, and extend their developing funds of knowledge.

We encourage those interested and invested in media literacy educationincluding, but not limited to parents, teachers, administrators, researchers, journalists, politicians, and think tanks - to grow opportunities for media literacy to be included in state and national educational standards and teacher education

programs. We contend that media literacy is more than a field of study needed to augment educational praxis to meet the demands of the twenty-first century. We posit that media literacy education is indispensable in reshaping and preserving the integrity of our democracy in light of changing information and communication technologies.

...we need to regenerate the roots of learning. The mere assemblage of facts, no matter how great, is of no worth without the habit of reflective inquiry to judge them. Inquiry is liberating. It empowers the learner and grants one dignity as a human being. The ability to ask a reflective question is the root of all change and progress. It formulates our perspective on the world and transforms one in the process. Reflective judgment is the core skill that 
initiates participants into the democratic process and revitalizes our democracy. (Deluty, 2010, p. 8)

As we enter into an unknown future, media literacy offers an enduring thread that may be capable of tying together educational praxis with our democracy as a way to sustain both. Through media literacy education as critical inquiry, people of all ages may gain deeper insight, abilities, and motivations to engage actively and at more complex levels with information in all forms.

\section{REFERENCES}

Alexander, P. A., Dinsmore, D. L., Fox, E., Grossnickle, E. M., Loughlin, S. M., Maggioni, L.,. . . Winters, F. I. (2011). Higher order thinking and knowledge: Domain-general and domain specific trends and future directions. In G. Schraw \& D. H. Robinson (Eds.), Assessment of higher order thinking skills (pp. 47-88). Austin, TX: Information Age Publishing.

American Library Association. (2015). Framework for information literacy for higher education. Retrieved from http://www.ala.org/acrl/standards/ilframework

Appalachian State University. (2014). CI2300: Teaching and learning in the digital age [course syllabus]. Boone, North Carolina: Theresa Redmond.

Appalachian State University. (2015). CI4830: Media literacy [course syllabus]. Boone, North Carolina: Theresa Redmond.

Arke, E. T., \& Primack, B. A. (2009). Quantifying media literacy: Development, reliability, and validity of a new measure. Educational Media International, 46(1), 53-56.

Bazalgette, C., (Ed.). (1989). Primary media education: A curriculum statement. London, England: British Film Institute.

Biggs, J. B., \& Collis, K. F. (1982). Evaluating the quality of learning: The SOLO taxonomy (Structure of the Observed Learning Outcome). New York, NY: Academic Press.

Biggs, J. B., \& Tang, C. S. (2011). Teaching for quality learning at university: What the student does. Maidenhead, England: McGraw-Hill Education.

Bloom, B. S. (Ed.), Engelhart, M. D., Furst, E. J., Hill, W. H., \& Krathwohl, D. R. (1956). Taxonomy of educational objectives: The classification of educational goals. Handbook 1: Cognitive domain. New York, NY: David McKay.

Buckingham, D. (2003). Media education: Literacy, learning and contemporary culture. Cambridge, MA: Polity Press.

Buckingham, D., \& Domaille, K. (2009). Making media education happen: A global view. In C. K. Cheung (Ed.), Media Education in Asia (pp. 19-30). doi:10.1007/978-1-4020-9529-0_3

Center for Media Literacy. (2011). Five key questions form foundation for media inquiry. Retrieved from http://www.medialit.org/reading-room/five-keyquestions-form- foundation-media-inquiry 
Chang, C., \& Lui, E. Z. (2011). Exploring the media literacy of Taiwanese elementary school students. The Asia-Pacific Education Researcher, 20(3), 604-611.

Considine, D., \& Haley, G. (1999). Visual messages: Integrating imagery into instruction (2nd ed.). Englewood, CO: Teacher Ideas Press.

Cortés, C. (2000). The children are watching: How the media teach about diversity. New York, NY: Teachers College Press.

DeCuir-Gunby, J. T., Marshall, P. L., \& McCulloch, A. W. (2011). Developing and using a codebook for the analysis of interview data: An example from a professional development research project. Field methods, 23(2), 136155.

Deluty, E. W. (2010). Asking questions: Cultivating the habit of inquiry. Thought \& Action, 135-138.

Duncan, B., D’Ippolito, J., Macpherson, C., \& Wilson, C. (1998). Mass media and popular culture. Toronto, ON: Harcourt.

Duran, R. L., Yousman, B., Walsh, K. M., \& Longshore, M. A. (2008). Holistic Media education: An assessment of the effectiveness of a college course in media literacy. Communication Quarterly, 56(1), 49-68.

EAVI. (2010). Study on assessment criteria for media literacy levels. Retrieved from http://ec.europa.eu/assets/eac/culture/library/studies/literacy-criteriareport en.pdf

EAVI. (2011). Testing and refining criteria to assess media literacy levels in Europe. Retrieved from https://eavi.eu/wp-

Content/uploads/2017/08/study_testing_and_refining_Ml_levels_in_europ e.pdf

Heine, C. (2013, October 21). Toys $R U_{s}$ ' holiday ads employ prankvertising element of surprise at center of huge effort. Retrieved from http://www.adweek.com/news/advertising-branding/toys-r-us-holiday-adsemploy-prankvertising-153296

Hobbs, R. (2007). Reading the media: Media literacy in high school English. New York, NY: Teachers College Press.

Hobbs, R. (2017a). Measuring the digital and media literacy competencies of children and teens. In F. C. Blumberg \& P. J. Brooks (Eds.), Cognitive development in digital contexts (pp. 253-274). Cambridge: Academic Press.

Hobbs, R. (2017b). Create to learn: Introduction to digital literacy. Hoboken, NJ: Wiley Blackwell.

Hobbs, R., \& Frost, R. (1998). Instructional practices in media literacy education and their impact on students' learning. The New Jersey Journal of Communication, 6(2), 123-148.

Hobbs, R., \& Frost, R. (2003). Measuring the acquisition of media literacy skills. Reading Research Quarterly, 38(3), 330-356.

Inan, T., \& Temur, T. (2012). Examining media literacy levels of prospective teachers. International Electronic Journal of Elementary Education, 4(2), 269-285. 
Jenkins, H., Purushotma, R., Weigel, M., Clinton, K., \& Robison, A. J. (2009). Confronting the challenges of participatory culture: Media education for the 21st century. Cambridge, MA: MIT Press.

Kellner, D., \& Share, J. (2005). Toward critical media literacy: Core concepts, debates, organizations and policy. Discourse: Studies in the cultural politics of education, 26(3), 369-386.

Kellner, D., \& Share, J. (2007). Critical media literacy is not an option. Learning Inquiry, 1(1), 59-69.

Kist, W. (2005). New literacies in action: Teaching and learning in multiple media. New York, NY: Teachers College Press.

Krippendorff, K. (2004). Content analysis: An introduction to its methodology (2nd edition). Thousand Oaks, CA: Sage.

Kuhn, D., Black, J., Keselman, A., \& Kaplan, D. (2000). The development of cognitive skills to support inquiry learning. Cognition and Instruction, 18(4), 495-523.

Lewis, A., \& Smith, D. (1993). Defining higher order thinking. Theory into Practice, 32(3), 131-137.

Maksl, A., Ashley, S., \& Craft, S. (2015). Measuring news media literacy. Journal of Media Literacy Education, 6(3), 29-45.

Martens, H. (2010). Evaluating media literacy education: Concepts, theories and future directions. Journal of Media Literacy Education, 2(1), 1-22.

Masterman, L. (1985). Teaching the media. London, England: Comedia.

McLuhan, M., \& Fiore, Q. (1967). The medium is the massage: An inventory of effects. New York, NY: Bantam Books.

Media Literacy Now. (n.d.). Your state legislation. Retrieved from https://medialiteracynow.org/your-state-legislation/

Mihailidis, P. (2014). Media literacy and the emerging citizen youth, engagement participation in digital culture. New York, NY: Peter Lang.

National Association for Media Literacy Education (NAMLE). (2007). Core principles of Media literacy education in the United States. Retrieved from https://namle.net/publications/core-principles.

National Association for Media Literacy Education (NAMLE). (2014). Key questions to ask when analyzing media messages. Retrieved from: https://drive.google.com/file/d/0B8j2T8jHrlgCZ2Zta2hvWkF0dG8/view

National Association for Media Literacy Education (NAMLE). (n.d.). Media literacy defined. Retrieved from http://namle.net/publications/medialiteracy-definitions/

Primack, B. A., Gold, M. A., Switzer, G. E., Hobbs, R., Land, S. R., \& Fine M. J. (2006). Development and validation of a smoking media literacy scale for adolescents. Archives of Pediatric and Adolescent Medicine, 160(4), 369374.

Primack, B. A., Sidani, J., Carroll, M. V., \& Fine, M. J. (2009). Associations between smoking and media literacy in college students. Journal of Health Communication, 14(6), 541-555.

Quin, R., \& McMahon, B. (1995). Evaluating standards in media education. Canadian Journal of Educational Communication, 22(1), 15-25. 
Ramsden, P. (1992). Learning to teach in higher education. New York, NY: Routledge.

Redmond, T. (2012). The pedagogy of critical enjoyment: Teaching and reaching the hearts and minds of adolescent learners through media literacy education. Journal of Media Literacy Education, 4(2), 106-120.

Redmond, T. A. (2016). Learning to teach the media: Pre-service teachers articulate the value of media literacy education. In M. N. Yildiz \& J. Keengwe (Eds.), Teacher education: Concepts, methodologies, tools, and applications (pp. 993-1015). Hershey, PA: IGI Global.

Redmond, T., Schilder, E., \& Moore, D.C. (2016). Learning to question: Developing an evidence-based framework to evaluate media literacy habits of inquiry. Media Education Research Journal, 7(1), 56-75.

Rickles, M. L., Schneider, R. Z., Slusser, S. R., Williams, D. M., \& Zipp, J. F. (2013). Assessing change in student critical thinking for introduction to sociology classes. Teaching Sociology, 41(3), 271-281.

Schilder, E. (2014). Perceptions of media literacy assessment: A mixed methods study. (Doctoral dissertation, Virginia Polytechnic Institute and State University). Retrieved from http://vtechworks.lib.vt.edu/bitstream/handle/10919/47727/Schilder_EA_ D_2014.pdf

Schilder, E., Lockee, B., \& Saxon, D. P. (2016). The challenges of assessing media literacy education. Journal of Media Literacy Education, 8(1), 3248.

Schmidt, H. C. (2013). Media literacy education from kindergarten to college: A comparison of how media literacy is addressed across the educational system. Journal of Media Literacy Education, 5(1), 295-309.

Share, J., Jolls, T., \& Thoman, E. (2005). Five key questions that can change the world: Classroom activities for media literacy. Center for Media Literacy. Retrieved from https://www.medialit.org/reading-room/five-keyquestions-can-change-world

Share, J. (2009). Media literacy is elementary: Teaching youth to critically read and create media (Vol. 41). Peter Lang.

Schraw, G., \& Robinson, D. H. (2011). Conceptualizing and assessing higher order thinking skills. In G. Schraw \& D. H. Robinson (Eds.), Assessment of higher order thinking skills (pp. 1-18). Austin, TX: Information Age Publishing.

Thoman, E. (n.d.). Skills \& strategies for media education. Retrieved from http://www.medialit.org/reading-room/skills-strategies-media-education

Torres, M., \& Mercado, M. (2006). The need for critical media literacy in teacher education core curricula. Educational Studies, 39(3), 260-282.

UNESCO. (2013). Global media and information literacy assessment framework: Country readiness and competencies. Paris, France. Retrieved from http://unesdoc.unesco.org/images/0022/002246/224655e.pdf

Vraga, E. K., Tully, M., Kotcher, J. E., Smithson, A., \& Broeckelman-Post, M. (2015). A multi-dimensional approach to measuring news media literacy. Journal of Media Literacy Education, 7(3), 41-53. 
Wineburg, S., McGrew, S., Breakstone, J., \& Ortega, T. (2016). Evaluating information: The cornerstone of civic online reasoning. Stanford Digital Repository. Retrieved from http://purl.stanford.edu/fv751yt5934

Worsnop, C. M. (1996). Assessing media work. Mississauga, Ontario: Wright Communications.

Wulff, S. (1997). Media literacy. In W. G. Christ (Ed.), Media education assessment handbook (pp. 123-142). Mahwah, NJ: Erlbaum. 


\section{Appendix: Codebooks}

\section{Code Book for Concept}

\section{Code 1 \\ Purpose}

Definition: Questions focus on the purpose of the message, including aspects related to authorship, context of dissemination, and economics. Questions might focus on why the message was created and disseminated, when and how, by whom, and other inquiries about general intentions of the media.

\section{Sample Questions:}

- What is the purpose of this media?

- Who's paying for this commercial?

- What time of year would this media be played?

- When do you think this commercial aired on TV? Why?

- Would you say this media achieved its purpose? Explain.

\section{Code 2 \\ Text}

Definition: Questions focus on the explicit content of the text as a narrative, encompassing what is happening and who is involved. Questions typically require the answerer to recall or respond to the story of the media in some way.

\section{Sample Questions:}

- What are some things that stood out to you during this video?

- Name one toy chosen by an individual child.

- What was the age range of the children in this advertisement?

- What would be a good title for this video?

- Without watching this ad again, what's the first thing you recall about it?

\section{Code 3 \\ Production}

Definition: Questions focus how the media was constructed, what production techniques were used, and why these techniques were used. For example, lighting, music, framing, camera language, and other audio-visual elements.

\section{Sample Questions:}

- What aesthetic values does this clip portray (imagery, lighting, music, color, etc.)?

- What are some media techniques used in creating this video that helped keep you (the audience) engaged?

- What might have been the purpose to providing close-up shots of the children holding and playing with their toys?

- Is there any significance to showing the children's reactions to the leaf lesson 
at the start of the video?

- Why would the makers decide to surprise the children instead of telling them where they're going?

\section{Code 4 \\ Audience}

Definition: Questions focus on who the audience is in general terms, in addition to eliciting information about the experiences, interpretations, emotions, or opinions of the viewers/audiences of the ad, including their subsequent feelings, physical responses, and actions.

\section{Sample Questions:}

- Who is this media directed towards?

- How did this clip make you feel?

- After watching that, what did you immediately want to do?

- If you could rank your mood, 1 being bad 10 being great, what mood are you in after watching this ad?

- How does this video change your view about Toys R Us?

\section{Code 5 \\ Representations}

Definition: Questions focus on the implicit content of the text and issues related to representations, ideologies, and values. Questions provide an entry for the answerer to consider how media impact social norms and cultures, including conceptions of gender, race, ethnicity, sexuality, etc.

\section{Sample Questions:}

- What does it mean that children are eager to contribute to consumerism but aren't interested in nature knowledge?

- What do you think caused the students to go for what we would consider gender specific toys? And why?

- Media portrays political and social values. What values does this clip portray? How do you know?

- Does the toy a child picked indicate anything specific about them? If yes, what?

- How does this video represent race?

\section{Code 6 \\ Realism}

Definition: Questions focus on eliciting information about the constructedness of the media, specifically prompting the answerer to critically consider the nature of the media in terms of reality. 


\section{Sample Questions:}

- Do you think the kids knew they were being filmed?

- Do you think this video was staged or were the children genuinely surprised?

- Do you believe that this ad was genuine emotion from the kids or was it scripted?

- How do you know that it is a commercial?

- Does this video seem like an advertisement?

\section{Code 7 \\ Not Critical}

These are unclear questions.

- Would you use this as a commercial?

- Was the media considering the image of the children's safety?

These questions reflect misconceptions.

- What reasons do you think Toys R Us might have had in organizing the trip?

- Do you think they want you to donate money to this cause?

These questions might not answer the research prompt.

- Who has a computer or phone they play with at home?

These questions might approach the media sample as content for teaching and learning with, rather than about media.

- If you were one of these kids, what would you have done in this situation?

These questions suggest that the questioner does not grasp the constructed nature of the media sample. In other words, these questions seem to be about the media as though it was real and suggest that the questioner embodies some level of media illiteracy.

- Is this an event that happens often?

- How would you compare this experience to other field trips?

\section{Code Book for Complexity}

\section{Code 0 \\ Not Critical, Prestructural}

Definition: These are questions that are: unclear, reflect misconceptions, do not answer the research prompt, approach the media as teaching content, or demonstrate that the questioner does not grasp the constructed nature of the media sample.

\section{Sample Questions:}

These are unclear questions.

- Would you use this as a commercial? 
- Was the media considering the image of the children's safety?

These questions reflect misconceptions.

- What reasons do you think Toys R Us might have had in organizing the trip?

- Do you think they want you to donate money to this cause?

- Is this a worthy cause in your eyes? Why or why not?

These questions might not answer the research prompt.

- Who has a computer or phone they play with at home?

These questions might approach the media sample as content for teaching and learning with, rather than about media.

- If you were one of these kids, what would you have done in this situation?

These questions suggest that the questioner does not grasp the constructed nature of the media sample. In other words, these questions seem to be about the media as though it was real and suggest that the questioner embodies some level of media illiteracy.

- Is this an event that happens often?

- How would you compare this experience to other field trips?

- Is there a way that trip could have been made more interesting, even to become more exciting like the Toys R Us trip?

- Do you think these kids would have had opportunities to get toys from Toys R Us otherwise?

- Do you think these gifts will be meaningful to the kids?

Code 1
LOW, Unistructural
Definition: Questions tend to focus on one piece of basic or fixed information that is
readily identifiable within the media—recalling, listing, naming, describing - and do not
require evidence to back up responses.
Sample Questions:
- What were the reactions of most of the students?
- What was used to film this?
- Who were these children?
Dhat type of media is this?
Definition: Questions focus on breaking down main ideas and information-reasoning
with information or analyzing- but do not examine relationships or require evidence-
based thinking. The questioner becomes an active negotiator of meaning; there is no fixed
answer. Questions may focus on one or more dimensions or aspects.
Sample Questions:
- How did this clip make you feel?


- Where do you think these kids come from (economically)?

- Marketing wise, do you think this is a well put together commercial?

- Does this media make you want to go to Toys R Us?

\section{Code 3}

\section{HIGH, Relational}

Definition: Questions focus on breaking down main ideas and information-analyzing to determine relationships or integrate aspects - and may reflect evidence-based thinking. Questions focus on one or more dimensions or aspects as conceptually integrated.

\section{Sample Questions:}

- The children all picked different toys do you feel that the toy they picked reflects something about the children?

- Why do you think the producer chose to use such bright colors in this video?

- Some kids picked smaller toys than others, why?

- Why were they more excited about toys than about a nature park?

\section{Code 4}

\section{HIGH, Extended Abstract}

Definition: Questions focus on extending ideas and information into other domains or contexts in new ways - connecting, synthesizing, and transforming.

\section{Sample Questions:}

- What messages does this video send about American ideals?

- How does this video portray science in schools?

- Why did they show the girl talking about the princesses?

- Why did they begin with nature education and end with consumerism?

- How would you have made this commercial? Would you have changed anything? 